\title{
Ensino de ciências em Braille com histórias em quadrinhos roteirizados por cegos
}

\author{
Otacílio Antunes Santana \\ Universidade Federal de Pernambuco
}

\section{Resumo}

A motivação deste trabalho foi a construção de objetos educacionais adaptados e avaliados por cegos, sem percepção de luz, dentro da temática do ensino de ciências. 0 objeto elaborado foi as histórias em quadrinhos (HQs), traduzidas em Braille, seguindo as demandas e roteiros construídos por cegos, com a avaliação de outras pessoas com algum grau de visão, buscando o entendimento, a aprendizagem e a satisfação do uso. Ao final, o objeto educacional construído foi disponibilizado no Banco Internacional de Objetos Educacionais.

Palavras-chave: Deficiência visual. Objeto de aprendizagem. Educação lúdica. 


\section{Science teaching in Braille with comics scripted by blind people}

The motivation for this article was the building of learning objects adapted and evaluated by blind people, with no light perception, within the subject area of science teaching. The object built was comics and their translation into braille, in accordance with the demands and scripts constructed by blind people, also evaluated by other people with some degree of vision, targeting understanding, learning and user satisfaction. Finally, the learning object built was made available in the International Database of Educational Objects.

Keywords: Visual impairment. Learning object. Playful education.

\section{Enseñanza de ciencias con historietas en Braille y guion hecho por ciegos}

La motivación de este trabajo fue la construcción de objetos pedagógicos adaptados y evaluados por ciegos sin percepción de luz, dentro de la temática de Enseñanza de Ciencias. El objeto elaborado fueron las Historietas y traducidas en Braile, siguiendo las demandas y guiones construidos por personas Ciegas, con la evaluación de otras personas con algún grado de visión, buscando la comprensión, el aprendizaje y la satisfacción del uso. Por último, el objeto pedagógico construido está disponible en la Base de Datos Internacional de Objetos Educativos.

Palabras-clave: Discapacidad visual. Objetos Educativos. La educación lúdica. 


\section{Introdução}

As principais bases legais nacionais para a temática da educação especial e sua perspectiva inclusiva se dão a partir da Lei de Diretrizes e Bases da Educação Nacional de 1961 (Lei no 4.024/61, Brasil, 1961); da Constituição da República Federativa do Brasil (Brasil, 1988), em seu artigo 208; e da Lei no 7.853/89 (Brasil, 1989), que já indicavam que o atendimento escolar às pessoas com necessidades especiais educacionais (Mantoan; Ropoli e Giffoni, 2012) e/ou transtorno globais de desenvolvimento (Mazzotta, 1987) seria, preferencialmente, dentro do sistema geral de ensino, o que garantiu a estas pessoas a matrícula em estabelecimentos escolares públicos e privados (Mazzotta, 2011). Isto certificado pela Declaração de Salamanca (1994) e pela Convenção da Guatemala (1999), somado ao tópico específico (Capítulo 8) descrito no Plano Nacional de Educação (Lei no 10.172/01, Brasil, 2001), fez emergir de forma sistemática e consistente a Política Nacional de Educação Especial na Perspectiva da Educação Inclusiva (Brasil, 2008), que em seu princípio maior defende “...o direito de todos os alunos de estarem juntos, aprendendo e participando sem nenhum tipo de discriminação" (Mazzotta, 2011). Os teóricos, em sua maioria, defendem que a educação especial deve ser inclusiva em classes e escolas comuns do ensino regular e que o docente deverá estar capacitado, e não especializado, para recepção, mediação e construção do conhecimento destes alunos (Araújo, Arantes e Klein, 2007; Baptista, 2009; Mantoan, 2011; Fleith e Alencar, 2013; Schlünzen e Rinaldi, 2014). A educação especial não é separada da educação regular, o que obriga o docente, em sua formação básica, ativa e permanente a estar preparado para uma sala de aula com um público diverso, não só com necessidades especiais educacionais, mas também diverso na cultura, na etnia, na raça e no socioeconômico. (Mantoan, 2011; Mantoan; Ropoli e Giffoni, 2012; Schlünzen e Rinaldi, 2014)

Criar programas e mecanismos é uma inquietação política, social e acadêmica, para que, no ambiente escolar, o estudante com necessidades especiais possa minimizar suas limitações frente às barreiras naturais e antrópicas (Esteve, 2004; Torres, Mazzoni e Mello, 2007; Mantoan, Ropoli e Giffoni, 2012). Por exemplo, para pessoas deficientes visuais, existem programas internacionais, como 'Previsão de Cegueira e Visão Parcial' da Organização Mundial da Saúde (WHO, 2013), e nacionais, como 'Livros para Cegos' do Ministério da Cultura (MinC, 2013), que incentivam a produção de objetos educacionais para inclusão intelectual destes alunos no espaço comum. É estimada a existência de 285 milhões de deficientes visuais no mundo, em que 39 milhões destes são cegos e 246 milhões possuem baixa visão e perda de visão progressiva (WHO, 2013). No Brasil, cerca de 500 mil pessoas são classificadas pelo Instituto Brasileiro de 
Geografia Estatística (IBGE, 2010) como deficientes visuais que não enxergam de maneira alguma.

0 conceito e denominação de 'cegos' neste trabalho será a mesma classificação de 'Blindness' pelo Conselho Internacional de Oftalmologia (ICOph, 2002), que descreveu que pessoas com esta classificação não enxergam e não possuem percepção de luz (no light perception), não inclusos aqui deficientes visuais com algum grau de visão ou percepção de luz e outras denominações, como pessoas com necessidades especiais no campo visual, "invidente" ou "invisual". Também neste trabalho será utilizada a classificação de i) cegueira congênita, aquela na qual o indivíduo nasce cego por uma anomalia ou má-formação antes do nascimento, e ii) cegueira adquirida, na qual o indivíduo nasce com algum grau de visão e, por alguma patologia (como catarata, glaucoma, retinopatia diabética, etc.), anomalia gênica (como, albinismo, síndrome de Bardet-Biedl, etc.), lesões ou intoxicações, perde a visão. (ICOph, 2002)

A construção de um objeto educacional (OE) é antecedida não só pela avaliação de sua demanda, como também pelo perfil do público-alvo que usará o objeto construído (Moreno, 2012). Informações como gênero, classe de idade, rendimento salarial familiar e nível de escolaridade devem ser variáveis fundamentais para construção da linguagem e aplicação dos conteúdos apreendidos (Yeni, 2012). Além destas informações, a percepção do públicoalvo, para relevância dos temas e sugestões, pode direcionar o construtor, ou sintetizador de informações, a suprir as necessidades de linguagem e adaptação deste objeto (Moreno, 2012; Yeni, 2012; Manzini et al., 2009). Com isso, duas avaliações deverão ser feitas: uma antes para avaliar este perfil e demanda e uma depois para avaliar a satisfação de uso, aprendizagem da temática e entendimento linguístico e funcional (Cechinel et al., 2013; Macedo e Ulbricht, 2012). No Banco Internacional de Objetos Educacionais (MEC, 2013), 19.666 OEs foram depositados; no Banco Mundial de Objetos Educacionais (Multimedia Educational Resource for Learning and Online Teaching - MERLOT) foram 41.186 OEs. Do somatório destes dois repositórios, apenas 0,001\% (61 OEs) possui alguma adaptação a pessoas com necessidades especiais e apenas $0,0001 \%$ ( 7 OEs) é adaptado aos cegos, carência também relatada em bibliotecas públicas. (Dallabrida e Lunardi, 2008)

Uma temática importante dentro do processo de ensino e aprendizagem é a de 'ciências', pois seus conceitos e suas práticas não se limitam a uma disciplina formal, como a própria ciências (ensino fundamental), nem a outras disciplinas do ensino médio (biologia, química, matemática, física e outras), nem às do ensino superior. A interdisciplinaridade, transdisciplinaridade e multidisciplinaridade dos conteúdos não restringem apenas a absorção de 
informação e conhecimento pelo sujeito de aprendizagem, mas também o processo de construção do conhecimento por meio da elaboração de hipóteses, passando pela execução de uma experimentação ou descoberta, até uma possível conclusão ou síntese de todo este processo (Silva e Krasilchik, 2013). 0 ensino de ciências é tratado então como um período de alfabetização científica em que o aluno aprende o conhecimento e o metaconhecimento, processo pelo qual se chega a comprovar uma determinada teoria, método ou enunciado (Morin, 1982). Este fundamento da metanálise, ensino de ciências, é importante em uma pós-modernidade em que se tem uma quantidade de dados brutos gerados a todo instante ('Big Data'), sem uma profunda análise de causa e efeito, ou com uma análise equivocada (Park e Leydesdorff, 2013; Bauman, 2001; Morin, 1982). Produtos e serviços resultados das ciências são geralmente relacionados com a melhoria da qualidade de vida, melhoria esta fundamental para o indivíduo com alguma necessidade especial. (Marques e Almeida, 2013; Tixier et al., 2013; Façanha et al., 2012)

Alguns objetos educacionais com temáticas de literatura científica foram propostos com sucesso no aprendizado e transmissão da informação, como no ensino da matemática (Marcone e Penteado, 2013) e adaptações de livros clássicos (Preto, 2009) para pessoas com cegueira, por meio do método Braille. Braille é um sistema de leitura em relevo, no qual o leitor pode fazê-lo com o tato, inventado pelo francês Louis Braille no ano de 1827. A unidade de leitura está disposta em uma célula braille, que possui 6 pontos de preenchimento, permitindo 64 combinações, que se traduzem em letras, símbolos, números, acentuações e pontuação (Jiménez et al., 2009). Com o sistema Braille foi possível traduzir textos e criar objetos educacionais adaptados à realidade dos cegos (Marcone e Penteado, 2013). Porém, a concepção de uma literatura em Braille e dos objetos educacionais parte de pessoas com algum tipo de visão, na qual apenas uma áudio descrição, ou simples tradução da Língua Portuguesa para o Braille, não permite um completo entendimento, como, por exemplo, a utilização de palavras com sentido abstrato (i.e. entardecer), sem uma prévia explicação para cegos congênitos. (Augestad, Klingenberg e Fosse, 2007)

Neste trabalho foi proposta a construção de histórias em quadrinhos (HQs) em Braille, seguindo as demandas e roteiros construídos por cegos e tendo a avaliação de outras pessoas com algum grau de visão, buscando não só o entendimento, como também a aprendizagem e a satisfação do uso. A HQ é uma união de quadros, que traz a impressão de um momento, sugerindo interação entre os personagens e o cenário. A cada mudança de quadro, seguindo um enredo, sugere uma movimentação sequencial e diálogos, e sua união constrói uma história que pode seguir o gênero de comédia, ação, drama e outros (Johnson, 
2012). As HQs são populares para todas as faixas etárias, por sua concisão no desfecho de cada história, pouco texto $(\leftarrow 500$ palavras em cada história) e por serem visualmente exploradas, mediante uma semiótica dos personagens, em que cada um traz alguma informação ou transmite algum vício, virtude ou luta por alguma causa (Cohn, 2010). Com isso, os objetivos deste trabalho foram: i) avaliar o perfil dos cegos nas unidades federativas brasileiras; ii) avaliar suas percepções quanto ao ensino de ciências; iii) construir histórias em quadrinhos roteirizados pelos cegos com temáticas do ensino de ciências; e iv) avaliar a $\mathrm{HQ}$ construída. $\mathrm{O}$ objeto educacional em questão priorizará a inclusão, para ser utilizado na classe comum, tanto para os alunos com necessidades especiais como para os que não possuem limitações visuais. (Esteve, 2004; Mantoan, 2011; Mantoan; Ropoli e Giffoni, 2012; Schlünzen e Rinaldi, 2014)

\section{Materiais e Métodos}

0 método foi dividido em duas partes. Primeiro foi amostrado um censo do perfil dos cegos nas unidades federativas do Brasil, registrando principalmente o número de leitores em Braille e suas percepções sobre o ensino de ciências. Na segunda parte, é descrita a construção da história em quadrinhos, focando o ensino de ciências, e posteriormente a avaliação deste objeto educacional construído.

\section{Perfil dos cegos nas unidades federativas brasileiras e percepções quanto ao ensino de ciências}

0 número de cegos foi estimado mediante verificação dos dados do censo do Instituto Brasileiro de Geografia e Estatística - IBGE (2010), por meio de associações, sociedades, organizações não governamentais, pastorais, igrejas, prefeituras, unidades regionais do IBGE e registros públicos abertos que pudessem estimar o número de cegos. Os dados foram coletados de janeiro de 2012 a julho de 2013. Neste levantamento, foram registrados o gênero, classe de idade, nível de escolaridade e rendimento salarial, conforme classes e métodos propostos pelo IBGE (2012), e o número de leitores em Braille.

Os leitores em Braille foram questionados por meio de entrevistas, registradas em um gravador Sony ICD-SX1000, com as seguintes perguntas: 1) Você já participou de alguma disciplina ou curso de ciências? (Possíveis respostas: sim / não); 2) Você consegue conceituar ciências? (Possíveis 
respostas: sim / não); 3) Você consegue produzir ciências? (Possíveis respostas: sim / não); 4) Aprendizagem de ciências é relevante? (Possíveis respostas: sim / não); 5) É possível ensinar ciências para cegos? (Possíveis respostas: concordo plenamente, concordo, indiferente e discordo, discordo plenamente); 6) É possível pessoas cegas ensinarem ciências para outro cegos? (Possíveis respostas: concordo plenamente, concordo, indiferente e discordo, discordo plenamente); 7) Qual a temática relevante para você na alfabetização científica? (Respostas: aberta); e 8) Qual a limitação hoje para o aprendizado da alfabetização científica? (Respostas: aberta); Autorização para entrevistas e divulgação do material foram registradas em áudio (Termo de Consentimento Livre e Esclarecido).

Nestes censos, limitações foram evidentes devido à falta de registros oficiais, dados obsoletos e registros de áreas não urbanas. 0 objetivo inicial deste censo não foi uma margem de acerto e, sim, uma listagem inicial que deverá ser acurada em outros censos. Outro objetivo é certificar uma suficiência amostral nacional que ajude na construção dos roteiros para as histórias em quadrinhos e que avalie este objeto educacional construído, mediante seus perfis e percepções.

\section{Construção da história em quadrinhos}

A construção da história em quadrinhos (HQ) seguiu oito passos (Figura 1). No início, alunos universitários do curso de ciências biológicas (licenciatura) da Universidade Federal de Pernambuco (Figura 1.1), já previamente conhecendo o resultado sobre as percepções dos cegos quanto ao ensino de ciências, realizaram entrevistas com aqueles que aceitaram construir roteiros para a elaboração de histórias em quadrinhos. Nestas entrevistas, inicialmente foram apresentados conceitos como histórias em quadrinhos, tópicos para a construção de roteiros dentro das artes cênicas (personagem, tempo, espaço, roteiro e movimentol e alguns tópicos sobre ciências.

$\mathrm{Na}$ segunda etapa, houve a decisão dos cegos juntamente com os alunos (Figura 1.2) da temática dentro do ensino das ciências, levando em consideração o contexto e perfil amostrado no item 2.1, como, por exemplo, trabalhar a temática da saúde, especificamente a questão da Dengue e erradicação do mosquito Aedes aegypti (Linnaeus, 1762). Decidida a temática, os cegos criaram isoladamente hipotéticos personagens, tempo, espaço, roteiro e movimento (Figura 1.3), registrados no gravador descrito. Todas as reuniões entre alunos e cegos foram gravadas, para que estes últimos pudessem lembrar das discussões e editar partes do roteiro. 
Figura 1: Sequência para construção da história em quadrinhos.

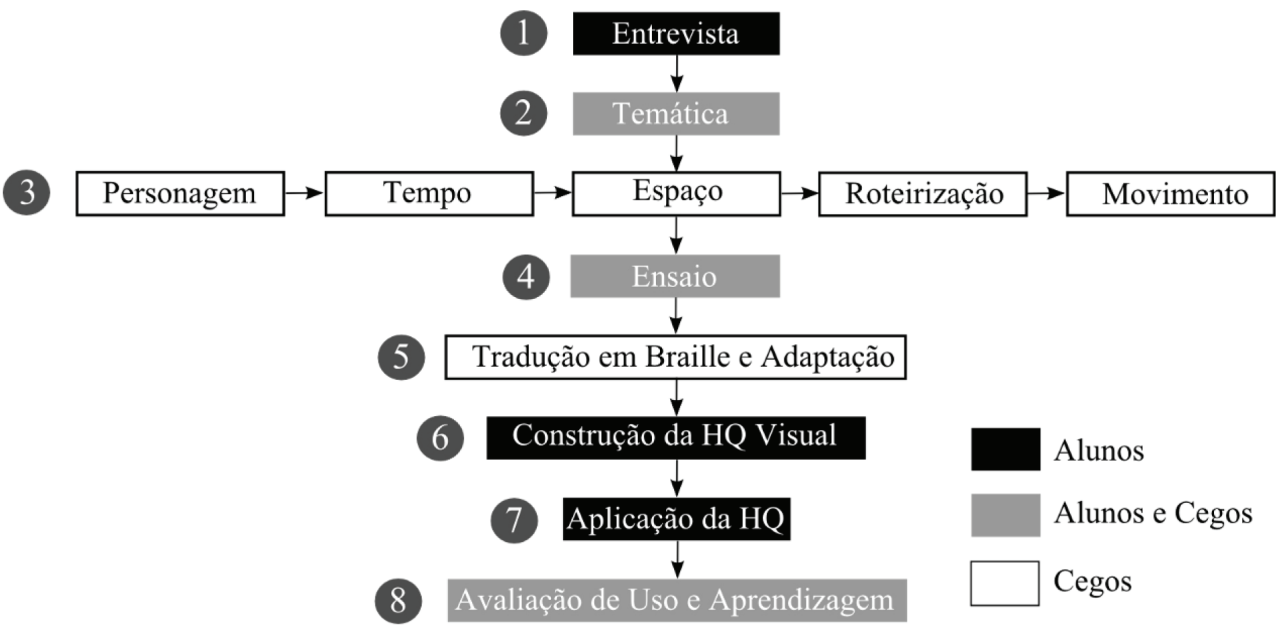

Fonte: Elaboração do autor, 2013.

Versões iniciais, denominadas de ensaio, foram construídas visualmente, adaptadas de acordo com as transcrições das gravações nos roteiros em Braille e apresentadas para os cegos (Figura 1.4). A parte visual foi realizada para mostrar aos que possuem algum grau de visão como seriam adaptações visuais de histórias roteirizadas por cegos. A partir daí, modificações e adaptações foram realizadas, principalmente de linguagem, para ficarem conceitualmente entendíveis para cegos congênitos e adquiridos. (Figura 1.5 e 1.6)

Nas últimas etapas, houve a aplicação ou distribuição para os leitores em Braille das HQs construídas (Figura 1.7), seguida de avaliação quanto ao entendimento (compreensão da linguagem), aprendizado da temática (apreensão da informação centrall e satisfação de uso (Figura 1.8). Para avaliação, houve a divisão em três grupos amostrais: i) cegos congênitos, ii) cegos adquiridos e iii) com visão. Outra avaliação foi se os grupos amostrais percebem diferenças entre as $H Q$ s apenas traduzidas em Braille e as $H Q s$ construídas mediante roteiros dos cegos. Para as duas avaliações, teste não paramétrico $X^{2}$ foi efetuado para o cálculo de $p$, no qual se observa a diferença entre os grupos amostrais $(p<0,05)$. 


\section{Resultados e Discussão}

\section{Perfil dos cegos nas unidades federativas brasileiras e percepções quanto ao ensino de ciências}

O censo estimou que, no Brasil, há 506.374 cegos e pôde certificar dentro deste grupo 19.988 leitores em Braille (Tabela 1). Os dados do IBGE (2010) em sua classificação apontam aproximadamente 500 mil deficientes visuais que não conseguem enxergar de modo algum - estimativa próxima à deste trabalho.

Do total, em 2012, 53\% são do gênero feminino (Figura 2) e em sua maioria $(29 \%)$ se situaram na faixa etária de 20 a 30 anos, seguidas pelas faixas etárias entre 30 e $40(20 \%)$, e entre 40 e 50 (17\%). Isto demostrou que muitos nascem com visão, mesmo que parcial, e a perdem principalmente na faixa etária de maior frequência de pessoas (Augestad, Klingenberg e Fosse, 2007). Outro destaque na questão das classes de idades foi o baixo número de pessoas registradas acima de 70 anos $(0,2 \%)$, indicando uma expectativa de vida menor do que a nacional, 74 anos. (IBGE, 2010)

Tabela 1: Censo de pessoas cegas, leitores em Braille cegos e roteiros enviados por unidade federativa brasileira.

\begin{tabular}{|c|c|c|c|c|}
\hline & $\begin{array}{c}\text { Unidade } \\
\text { Federativa }\end{array}$ & cegos & Braille & roteiros \\
\hline \multirow{7}{*}{$\mathrm{NO}$} & Rondônia & 2.294 & 123 & 5 \\
\hline & Acre & 1.41 & 67 & 4 \\
\hline & Amazônia & 8.214 & 108 & 9 \\
\hline & Roraima & 1.129 & 24 & 5 \\
\hline & Pará & 15.459 & 438 & 1 \\
\hline & Amapá & 1.325 & 212 & 8 \\
\hline & Tocantins & 2.577 & 169 & 7 \\
\hline \multirow{9}{*}{$\mathrm{NE}$} & Maranhão & 13.998 & 181 & 7 \\
\hline & Piauí & 7.559 & 511 & 5 \\
\hline & Ceará & 24.224 & 399 & 7 \\
\hline & $\begin{array}{l}\text { Rio Grande } \\
\text { do Norte }\end{array}$ & 6.929 & 706 & 3 \\
\hline & Paraíba & 8.477 & 301 & 10 \\
\hline & $\begin{array}{l}\text { Pernam- } \\
\text { buco }\end{array}$ & 19.95 & 691 & 8 \\
\hline & Alagoas & 6.977 & 514 & 7 \\
\hline & Sergipe & 4.069 & 298 & 9 \\
\hline & Bahia & 33.98 & 761 & 3 \\
\hline
\end{tabular}




\begin{tabular}{|c|c|c|c|c|}
\hline \multirow{4}{*}{ SE } & $\begin{array}{l}\text { Minas } \\
\text { Gerais }\end{array}$ & 45.015 & 3.007 & 12 \\
\hline & $\begin{array}{l}\text { Espírito } \\
\text { Santo }\end{array}$ & 7.298 & 809 & 5 \\
\hline & $\begin{array}{l}\text { Rio de } \\
\text { Janeiro }\end{array}$ & 53.178 & 1.761 & 2 \\
\hline & São Paulo & 14.3426 & 3.281 & 17 \\
\hline \multirow{3}{*}{ SU } & Paraná & 26.155 & 832 & 10 \\
\hline & Santa Catarina & 13.687 & 763 & 13 \\
\hline & $\begin{array}{l}\text { Rio Grande } \\
\text { do Sul }\end{array}$ & 28.748 & 1.462 & 5 \\
\hline \multirow{5}{*}{$\mathrm{CO}$} & $\begin{array}{c}\text { Mato Grosso } \\
\text { do Sul }\end{array}$ & 4.917 & 307 & 8 \\
\hline & $\begin{array}{r}\text { Mato } \\
\text { Grosso }\end{array}$ & 5.168 & 428 & 2 \\
\hline & Goiás & 13.775 & 761 & 8 \\
\hline & $\begin{array}{l}\text { Distrito } \\
\text { Federal }\end{array}$ & 6.436 & 1.074 & 11 \\
\hline & TOTAL & 506.374 & 19.988 & 189 \\
\hline
\end{tabular}

Fonte: elaboração do autor, 2013.

Figura 2: Perfil dos cegos ( $=506.374$ ): gênero, classe de idade, nível de escolaridade e rendimento salarial familiar (salário mínimo).
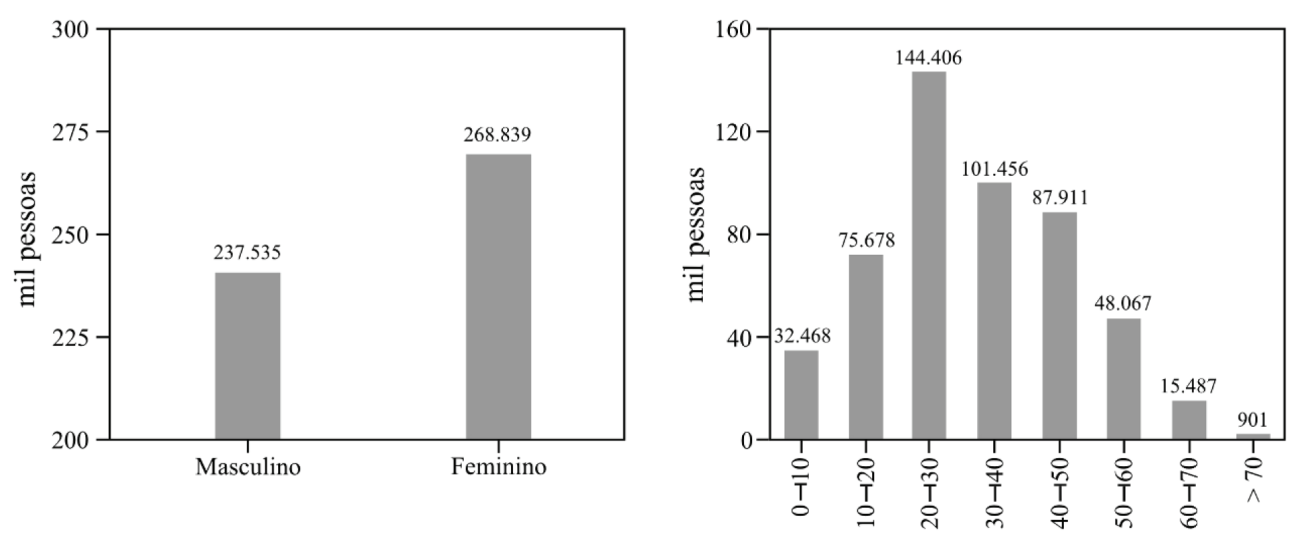

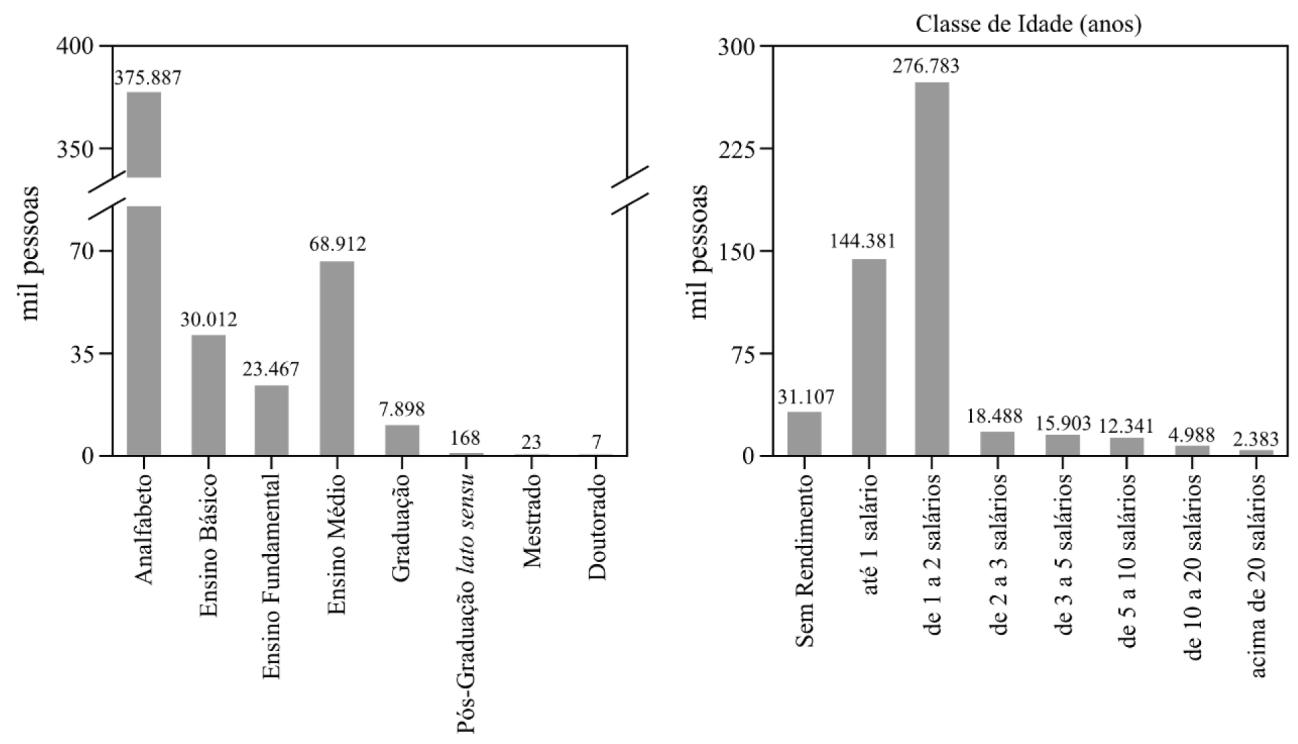

Fonte: elaboração do autor, 2013.

O nível de escolaridade dos cegos, em sua maioria (74\%), foi classificado como analfabeto, seguido pela conclusão do ensino médio (14\%) e o somatório dos ensinos básicos e fundamental (11\%). Analfabetos aqui incluem os que não sabem ler em Braille, ou outro método, e os que não possuem certificação escolar. Poucos concluem a graduação $(2 \%)$ e menos de $1 \%(0,03 \%)$ conclui algum tipo de pós-graduação (Figura 2). Destacaram-se a falta da capacitação do docente e da escola para o manejo deste tipo de estudante e a carência de uma infraestrutura das cidades que permita a mobilidade do cego (Schmidt et al., 2013; Sankako, 2009). E isto diretamente reflete no rendimento salarial familiar: a maior parte dos cegos (55\%) sobrevive com renda entre um e dois salários mínimos, e 35\% sobrevivem com menos do que um salário mínimo. Destes, a maioria vive com ajuda de custos do Governo Federal, mediante programas como o Benefício de Prestação Continuada da Assistência Social (BPC-LOAS) e Bolsa Família (Brasil, 2013). Outras causas refletem-se no baixo rendimento: não apenas a escolaridade, mas também o requerimento da visão na maioria das profissões formais e informais, como no quesito educação, na carência de mobilidade até o local trabalho e na adaptação da empresa ou instituição para receber uma pessoa com necessidades especiais. (Schmidt et al., 2013)

Outro perfil avaliado foi a percepção dos leitores em Braille levantada quanto ao ensino de ciências (Figura 3). Em relação às três primeiras perguntas, 54\% já participaram de alguma disciplina de ciências em qualquer nível escolar, 
formal ou informalmente; $17 \%$ retrataram que conseguem conceituar o que é ciências; e $5 \%$ conseguiriam produzir ciências, mediante seus conceitos. Os que responderam negativamente a estas duas últimas perguntas relataram uma percepção de que ciências, como área do conhecimento, somente é realizada em laboratórios, com vidrarias, reagentes e equipamentos lestufas, balança, bico de Busen, etc.), o que tornaria impossível a eles participar da produção de ciências.

Porém 99\% dos leitores em Braille confirmaram que a disciplina e os conteúdos de ciências são relevantes para sociedade civil; a porcentagem contrária (1\%) relatou que era religiosa praticante e que apenas os parâmetros religiosos (fé, penitência, crença, etc.) poderiam melhorar sua qualidade de vida. Oitenta e quatro por cento concordam plenamente e $16 \%$ concordam que é possível ensinar ciências não só como disciplina, mas também os conteúdos isoladamente. Setenta e quatro por cento concordam plenamente e $26 \%$ concordam que é possível um cego ensinar outro cego estes conteúdos. As pessoas com necessidades especiais confiam mais em outras com necessidades especiais próximas às delas, para a condução não só no ambiente, mas também em áreas acadêmicas, sociais e políticas, pois compactuam das mesmas limitações. (Mashal e Kasirer, 2012)

Os conteúdos mais relevantes apontados são saúde (46\%), alfabetização científica (34\%) e afirmações afirmativas (8\%), superando tópicos como meio ambiente (7\%) (Figura 3). Isso reforça a confiança dos cegos nas ciências, que, com seus produtos, poderão não só amortizar os impactos de sua necessidade especial frente à sociedade e ao ambiente, mas também recuperar a visão ou reduzir o número de cegueira congênita e adquirida (Refuveille, 2012). A questão ambiental e a transformação do ambiente em uma escala visual, mesmo que afete seus processos e sistema, não sensibilizaram os cegos como sensibilizaram os que possuem alguma visão. Se a transformação no ambiente não intoxica nem causa um efeito direto a eles, não se torna uma problemática principal. (Beechela, 1975)

Foi retirado da análise da limitação para o aprendizado da alfabetização científica o quesito 'mobilidade' até o estabelecimento educacional, que inicialmente foi apontado por $100 \%$ dos entrevistados, conforme discutido anteriormente. 0 intento desta pergunta foi se, com a criação do objeto educacional, eles poderiam construir o conhecimento em qualquer lugar e tempo, sem estarem inseridos em uma educação formal. Então, as principais limitações apontadas para a carência da aprendizagem da alfabetização científica está principalmente na linguagem do método (38\%), nos objetos educacionais (32\%) e nos cursos adaptados (25\%). Este dado corroborou com a 
hipótese de que a tradução em Braille apenas de uma literatura ou de um objeto educacional não permite a compreensão deles integralmente (Matsuda et al., 2010; Nicolaiewsky e Correa, 2008). Associada a isso, a carência de objetos educacionais e de cursos adaptados. Outro ponto relatado é a falta de uma base de dados centralizada específica para pessoas com necessidades especiais. (Dodd et al., 2010)

Figura 3: Respostas às perguntas: 1) Você já participou de alguma disciplina ou curso de ciências?; 2) Você consegue conceituar ciências?; 3) Você consegue produzir ciências?; 4) Aprendizagem de ciências é relevante?; 5) É possível ensinar ciências para cegos?; 6) É possível cegos ensinarem ciências para outro cegos?; 7) Qual a temática relevante para você na alfabetização científica?; e 8)

Qual a limitação hoje para o aprendizado da alfabetização científica?

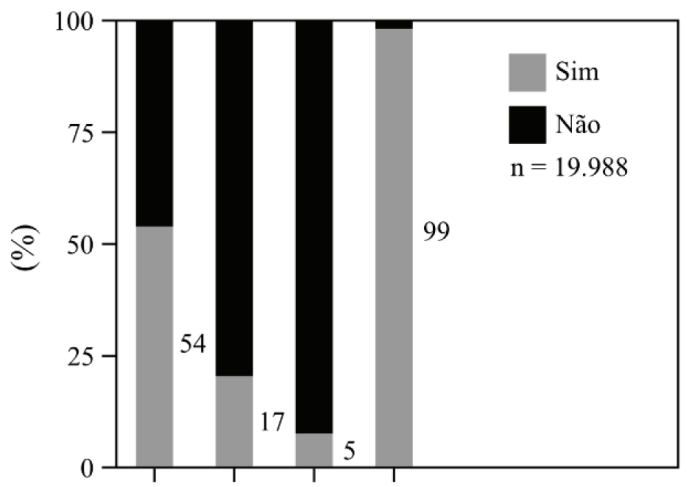

$\begin{array}{llll}1 & 2 & 3 & 4\end{array}$

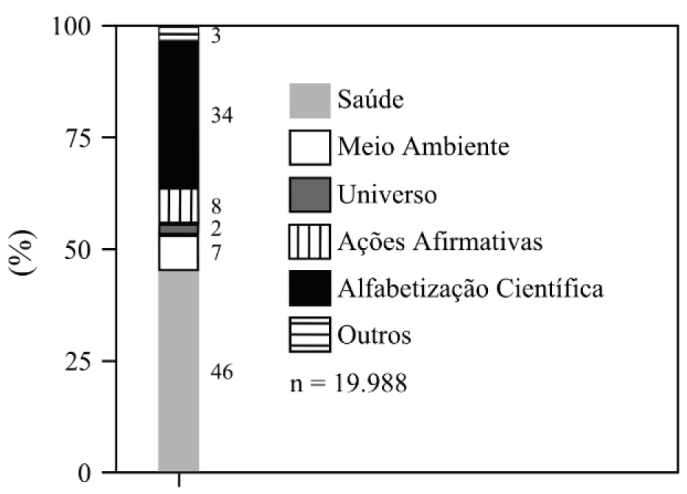

7

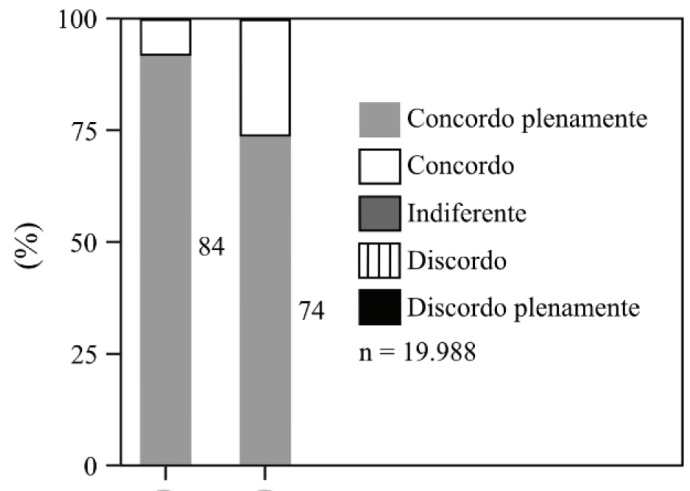

5

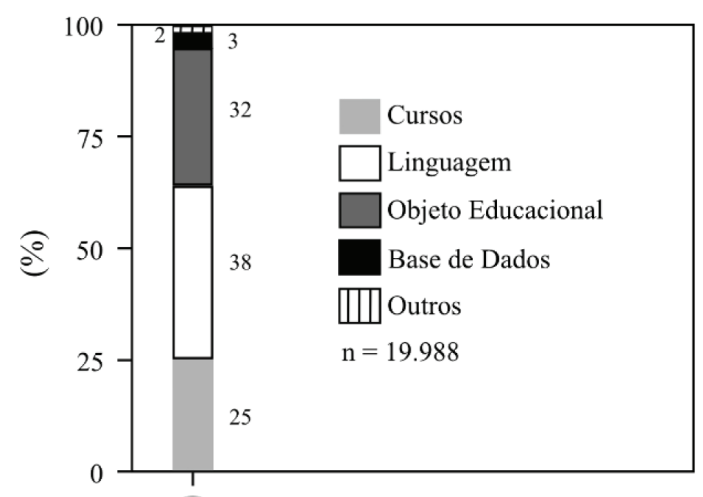

8

Fonte: elaboração do autor, 2013. 


\section{Construção da história em quadrinhos}

Foram recebidos 189 roteiros (Tabela 1), com a participação de todas as unidades federativas brasileiras na construção de histórias em quadrinhos. Inicialmente, todos os roteiros seriam transformados em HQ, porém observouse que algumas histórias sobrepunham temáticas ou personagens que foram integradas, conforme autorização dos autores. Foi decida, então, a construção de 60 histórias em quadrinhos.

Os personagens seguiram duas correntes, i) os comuns do dia a dia e reais (Figura 4A), estereotipados com profissões e faixa etárias distintas (Johnson, 2012), e ii) os imaginários (Figura 4B), tomado o parâmetro maniqueísta do bom contra o mau, conforme a literatura clássica infanto-juvenil (Houser, 2010). 0 ensaio foi a primeira versão, elaborada pelos alunos universitários, para apresentar aos cegos e verificar se aquilo que estava registrado no gravador fora fielmente transcrito, conforme o que os autores dos roteiros planejaram (Figura 5). Nos ensaios, as personagens, cenário e o roteiro foram acrescidos, como também foi definido o enredo. A partir da finalização do enredo, foram construídos então, o visual, implantação da cena e movimentos (Figura 6), a aplicação do cenário (Figura 7) e a finalização das histórias (Figura 8).

Figura 4: Construção inicial dos personagens transcritos: a) personagens comuns e b) personagens imaginários.
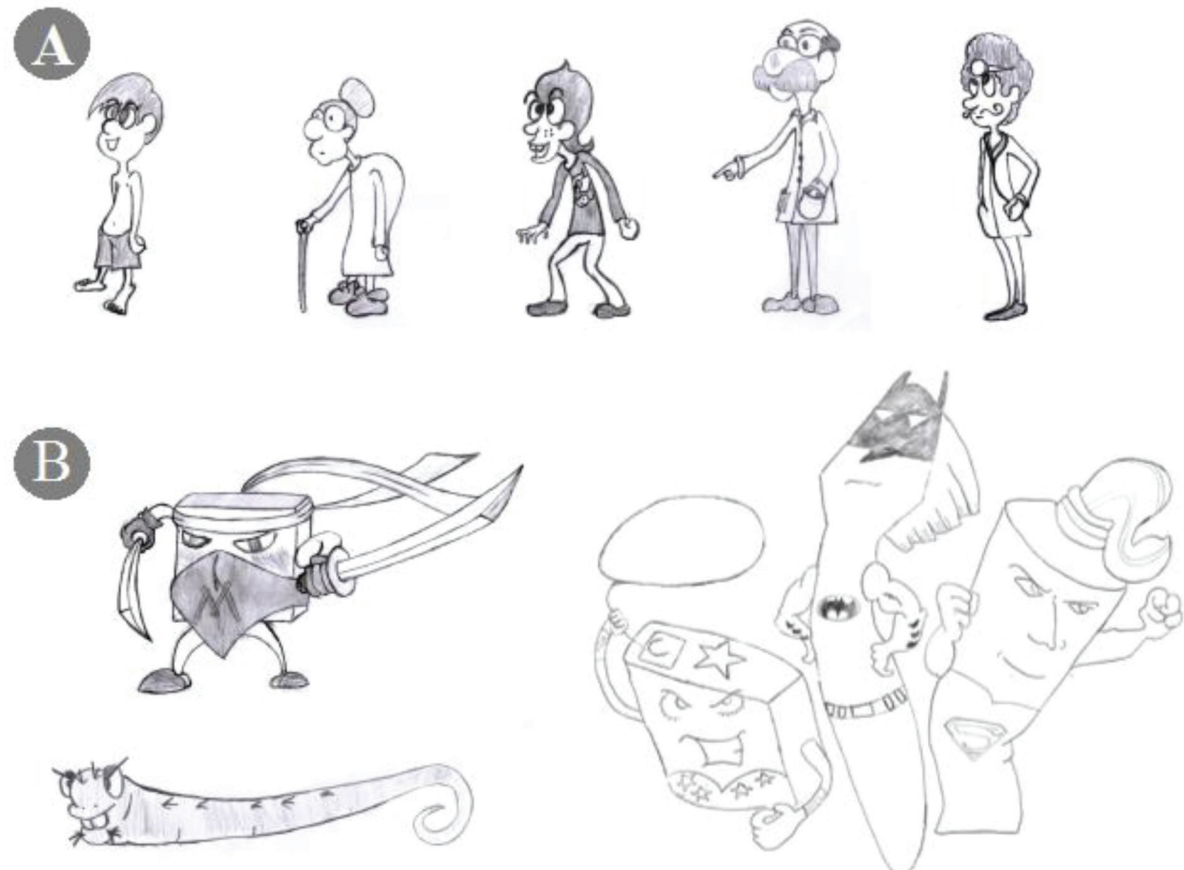

Fonte: Elaboração dos alunos de licenciatura em Ciências Biológicas da Universidade Federal de Pernambuco, 2013. 
Figura 5: Exemplo de ensaio de história em quadrinhos: al descrição dos personagens, tradução em Braille na seta; b) leitura em Braille das histórias construídas; e cl enredo da história em Braille.

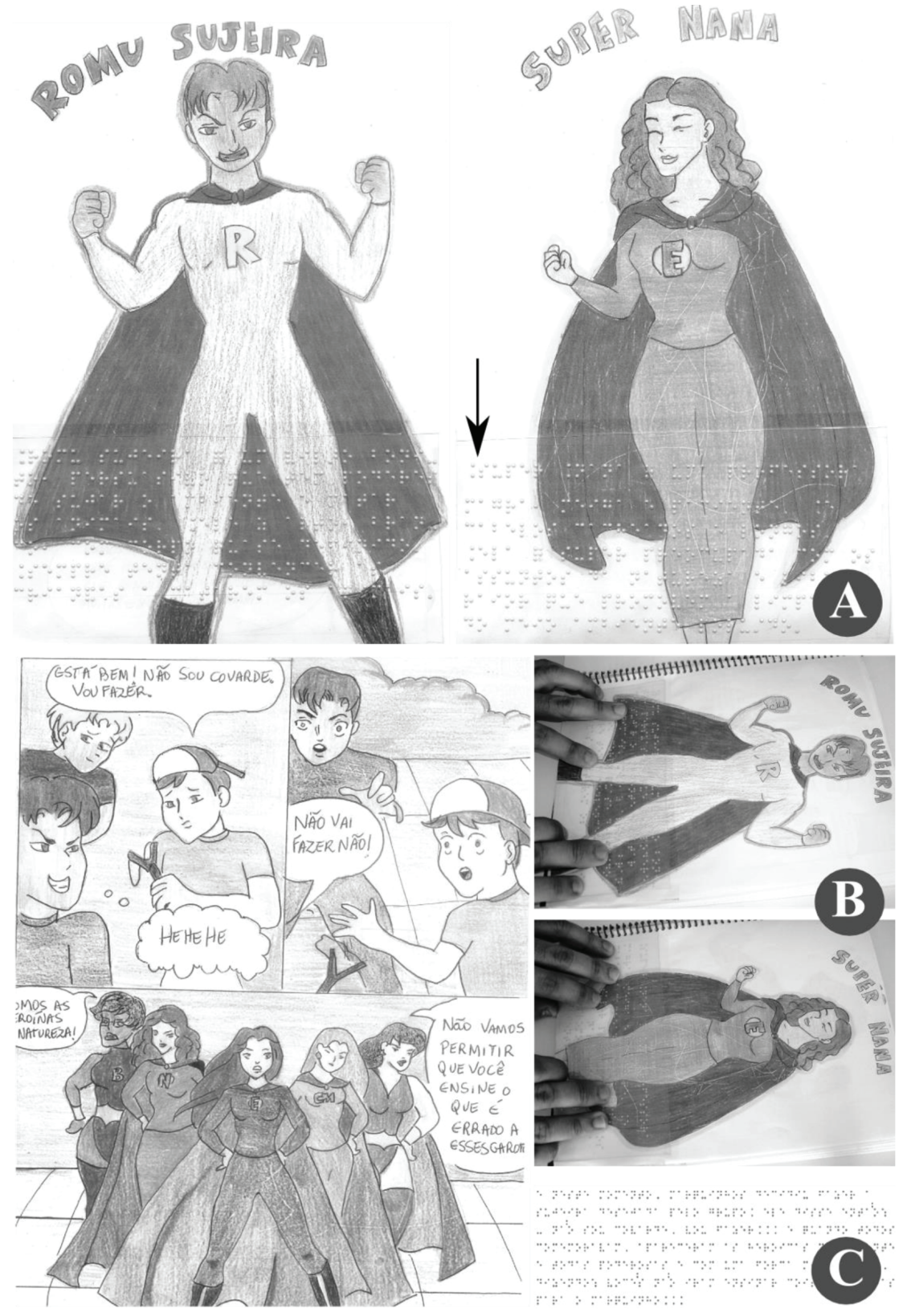

Fonte: Elaboração dos alunos de licenciatura em Ciências Biológicas da Universidade Federal de Pernambuco, 2013. 
Figura 6: Construção das cenas e movimentos das histórias em quadrinhos.

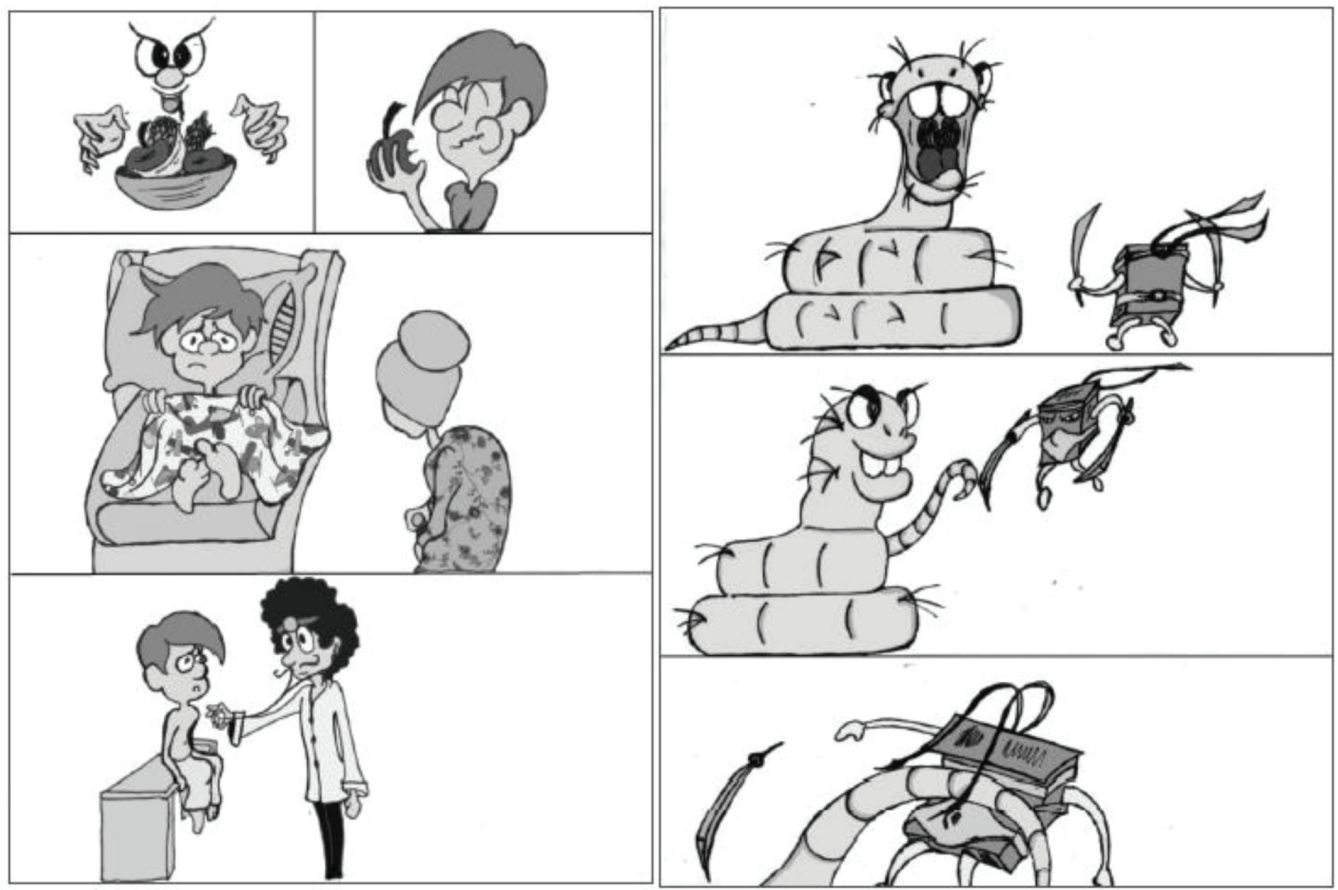

Fonte: Elaboração dos alunos de licenciatura em Ciências Biológicas da Universidade Federal de Pernambuco, 2013.

Figura 7: Construção do cenário das histórias em quadrinhos e inserção das falas.
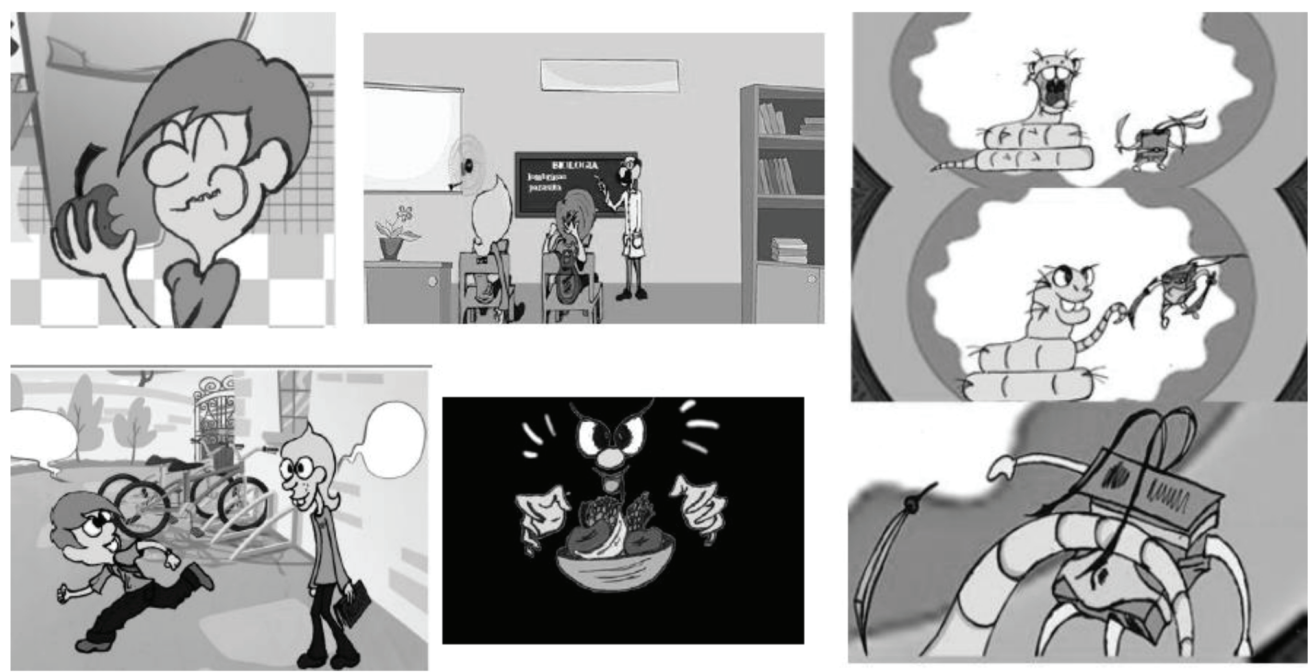

Fonte: Elaboracão dos alunos de licenciatura em Ciências Biológicas da Universidade Federal de Pernambuco, 2013. 
Figura 8: Finalização das histórias em quadrinhos, tradução e adaptação em Braille.

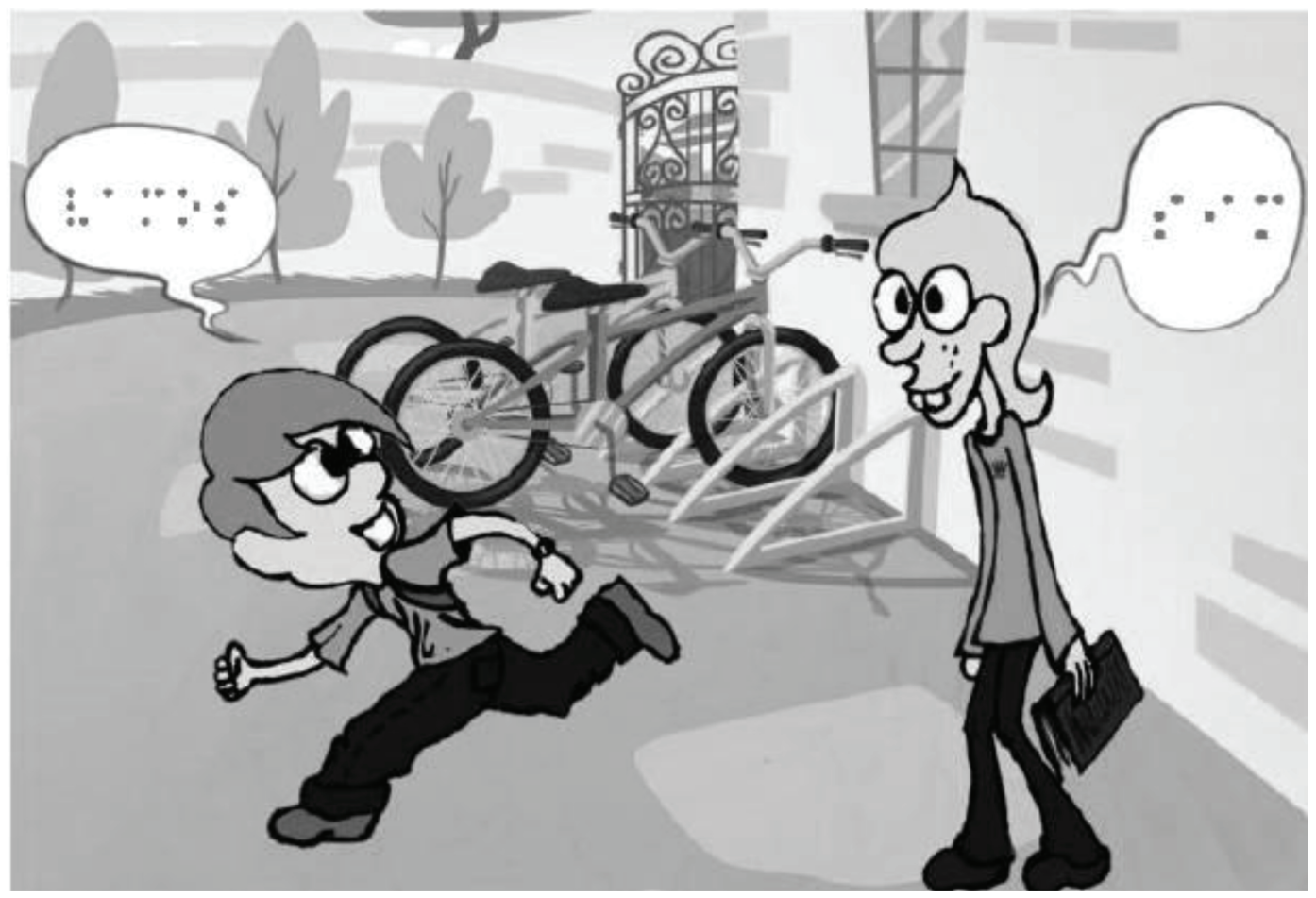

Fonte: Elaboração dos alunos de licenciatura em Ciências Biológicas da Universidade Federal de Pernambuco, 2013.

$\mathrm{Na}$ avaliação das 60 histórias em quadrinhos pelos grupos amostrais (Figura 9), pessoas com cegueira congênita, cegueira adquirida e com visão concordaram plenamente (> $65 \%$ ) e concordaram (> 35\%) que todas foram entendidas, que aprenderam o conteúdo e ficaram satisfeitos com o uso. Não houve diferenças significativas $(p>0,05)$ entre os grupos. Para as pessoas com cegueira adquirida, apenas $1 \%$ se mostrou indiferente quanto à satisfação do uso da história em quadrinhos, relatando que prefere aprender ciências por meio de áudio, 'uma leitura passiva' (Veispak, Boets e Ghesquière, 2013). Estes parâmetros (compreensão, apreensão e satisfação) validam temporalmente o objeto educacional construído, pois, como qualquer recurso didático, ele é dinâmico, sofre avaliações e modificações constantes conforme sua contextualização no tempo e espaço. (Boyle, 2003) 
Figura 9: Avaliação da interação com a história em quadrinhos roteirizados por cegos, pelos três grupos amostrais quanto ao entendimento (compreensão da linguagem), aprendizado da temática (apreensão da informação central) e satisfação de uso. $P=$ resultado do teste $X^{2}$.

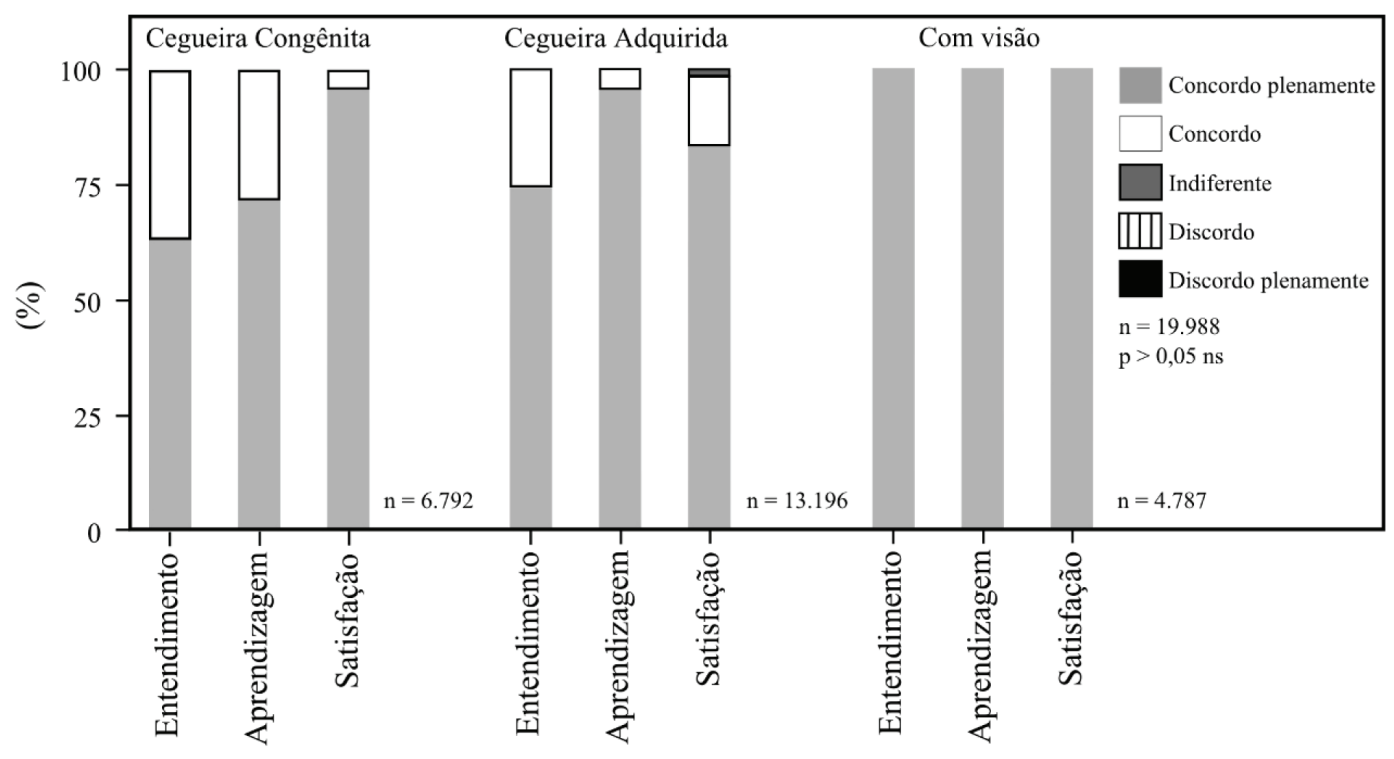

Fonte: Elaboração do autor, 2013.

Ao questionamento: Você percebe diferenças entre as histórias em quadrinhos apenas traduzidas em Braille e as histórias roteirizadas por cegos? (Figura 10). Noventa e sete por cento das pessoas com cegueiras congênitas e $93 \%$ das pessoas com algum grau de visão afirmaram que perceberam esta diferença. Para o grupo de cegueiras adquiridas, $74 \%$ afirmaram isto, fazendo com que houvesse diferença entre os grupos amostrais $(p<0,001)$. Este grupo, por algum período da vida, teve algum grau de visão, conseguiu construir imagens e situações mentalmente (Rabello, Motti e Gasparetto, 2007), diferentemente das pessoas com cegueira congênita, que não tiveram uma relação conceitual e visual de um objeto ou situação em seu passado. 
Figura 10: Resposta ao questionamento: Você percebe diferenças entre as histórias em quadrinhos apenas traduzidas em Braille e as histórias roteirizadas por cegos? Pelos grupos amostrais avaliados ( $\mathrm{P}=$ resultado do teste $\left.\mathrm{X}^{2}\right)$.

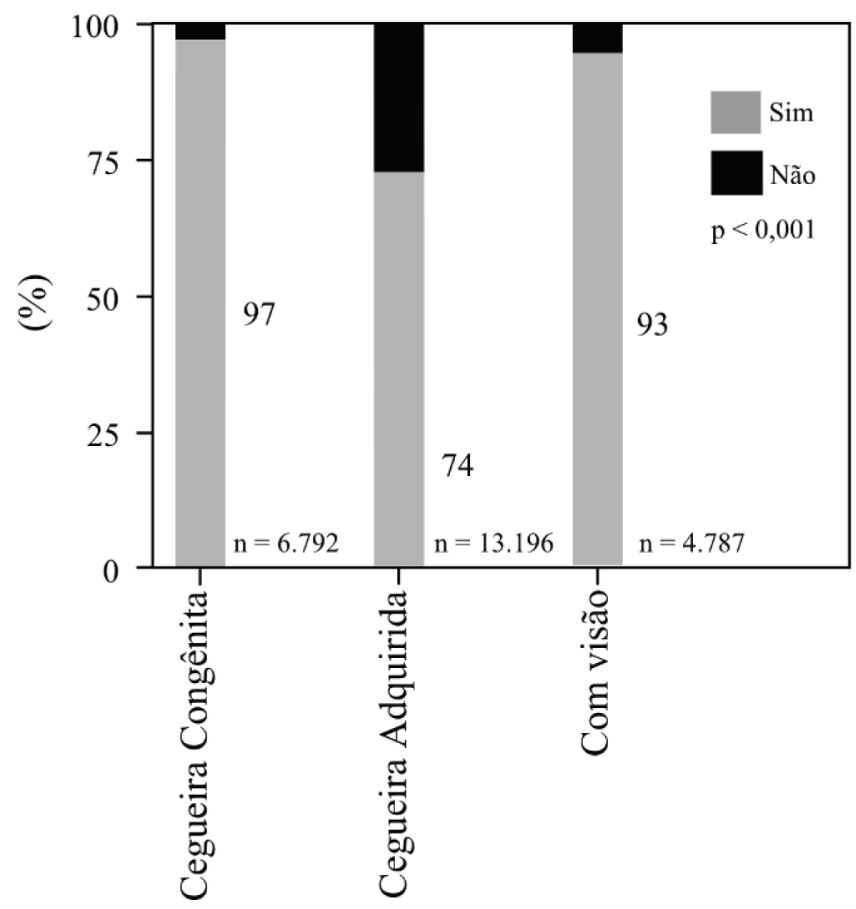

Fonte: Elaboração do autor, 2013.

\section{Considerações Finais}

A construção das histórias em quadrinhos roteirizada pelos cegos e seguindo suas demandas, adaptações e perfis foi um sucesso quanto ao entendimento, compreensão e satisfação. Há uma carência mundial deste tipo de objeto educacional, que existe disponível via mercado ou governo, por meio de livros e objetos traduzidos em Braille, mas com a concepção de pessoas com algum tipo de visão. As temáticas apresentadas no ensino de ciências mostraram a relevância que o tema possui para a redução ou prevenção dessa necessidade especial. A sedução da alfabetização científica via histórias em quadrinhos se mostra uma ferramenta possível para que o público-alvo estudado seja instigado para sua inserção na construção do metaconhecimento não só a seu favor, mas de toda população. 0 ponto relevante deste trabalho foi o processo de construção 
da história pelos cegos, como se fosse um 'quebra-cabeça', em que cada peça (personagem, figurino, cenário, movimento, enredo e falas) ao final se encaixasse em um contexto com significado, etapas estas importante para construção do conhecimento científico.

De maneira pragmática, o objeto educacional construído poderá ser utilizado na sala de aula comum, o que ao mesmo tempo atende a alunos com e sem necessidades especiais, conforme indicações da Política Nacional de Educação Especial na Perspectiva da Educação Inclusiva. Sua utilização em ambientes não formais também é recomendada, dado o didatismo da linguagem e acesso. 0 depósito no Banco de Dados Internacional de Objetos Educacional visa à sua disseminação - um feedback dos usuários, indicado e solicitado ao final das histórias em quadrinhos, estimulará novas versões, que serão adaptadas tendo em vista a contextualização espacial e temporal de seu uso.

\section{Referências}

ARAÚJO, U. F.; ARANTES, V. A.; KLEIN, A. M. Ética e Cidadania: Inclusão e Exclusão Social. 1. ed. v. 4. 180p. Brasília - DF: Ministério da Educação, Secretaria de Educação Básica, 2007.

AUGESTAD, L. B.; KLINGENBERG, O.; FOSSE, P. Braille use among Norwegian children from 1967 to 2007: trends in the underlying causes. Acta Ophthalmologica, Reykjavík, v. 90, pp. 428-434, 2012.

BAPTISTA, C. R. Inclusão e escolarização: múltiplas perspectivas. 2. ed. v. 1. 192p. Porto Alegre: Mediação, 2009.

BAUMAN, Z. Modernidade Líquida. 260p. Editora: Zahar. 2001.

BEECHELA, J. Interpretation for Handicapped Persons. The Journal of Environmental Education, Philadelphia, v. 6, n. 4, pp. 34-44, 1975.

BOYLE, T. Design principles for authoring dynamic, reusable learning objects. Australian Journal of Educational Technology, Wagga, v. 19, n. 1, pp. 46-58, 2003.

BRASIL. Lei no 4.024, de 20 de dezembro de 1961. Fixa as Diretrizes e Bases da Educação Nacional. Disponível em: <http://www2.planalto.gov.br/>. Acesso em: jan. 2013.

BRASIL. Constituição da República Federativa do Brasil. Promulgada em 5 de outubro de 1988. Disponível em: <http://www2.planalto.gov.br/>. Acesso em: jan. 2013.

BRASIL. Lei $n^{0} 7.853$, de 24 de outubro de 1989. Dispõe sobre o apoio às pessoas portadoras de deficiência, sua integração social, sobre a Coordenadoria Nacional para Integração da Pessoa Portadora de Deficiência - Corde, institui a tutela jurisdicional de interesses coletivos ou difusos dessas pessoas, disciplina a 
atuação do Ministério Público, define crimes, e dá outras providências. Disponível em: <http://www2.planalto.gov.br/>. Acesso em: jan. 2013.

BRASIL. Lei n ${ }^{\circ}$ 10.172, de 9 de Janeiro de 2001. Aprova o Plano Nacional de Educação e dá outras providências. Disponível em: <http://www2. planalto.gov.br/>. Acesso em: jan. 2013.

BRASIL. Política Nacional de Educação Especial na Perspectiva da Educação Inclusiva. (07 de janeiro de 2008). Disponível em: <http://peei.mec.gov.br/arquivos/ politica_nacional_educacao_especial.pdf $>$. Acesso em: jan. 2013.

BRASIL. Presidência da República. Disponível em: <http://www2.planalto.gov. br/>. Acesso em: jan. 2013

CECHINEL, C.; SICILIA, M. Á.; SÁNCHEZ-ALONSO, S.; GARCÍA-BARRIOCANAL, E. Evaluating collaborative filtering recommendations inside large learning object repositories. Information Processing \& Management, Lugano, v. 49, n. 1, pp. 34-50, 2013.

COHN, N. Extra! Extra! Semantics in comics!: The conceptual structure of Chicago Tribune advertisements. Journal of Pragmatics, Lancaster, v. 42, n. 11, pp. 31383146, 2010.

DALLABRIDA, A. M.; LUNARDI, G. M. 0 acesso negado e a reiteração da dependência: a biblioteca e o seu papel no processo formativo de indivíduos cegos. Cadernos Cedes, Campinas, v. 28, n. 75, pp. 191-208, 2008.

DODD, P.; CRAIG, S.; KELLY, F.; GUERIN, S. An audit of the Irish National Intellectual Disability Database. Research in Developmental Disabilities, Baton Rouge, v. 31, n. 2, pp. 446-451, 2010.

ESTEVE, J. M. A terceira Revolução Educacional: a educação na sociedade do conhecimento. 207 p. São Paulo: Moderna, 2004.

FAÇANHA, A. R.; LIMA, L. S.; ARAÚJO, M. C. C.; CARVALHO, W. V.; PEQUENO, M. C. Auxiliando o Processo de Ensino-Aprendizagem do Braille Através de Dispositivos Touch Screen. Informática na Educação: teoria e prática, Porto Alegre, v. 15, n. 2 pp. 153-169, 2012.

FLEITH, D. de S.; ALENCAR, E. M. L. S. Superdotados. Trajetórias de Desenvolvimento e Realizações. 1. ed. v. 1. 230p. Curitiba: Juruá Editora, 2013.

HOUSER, H. Comic Crisis. American Book Review, Victoria, v. 32, n. 1, pp. 1-10, 2010. IBGE - Instituto Brasileiro de Geografia e Estatística. Estadosla. Disponível em: <http://www.ibge.gov.br/estadosat/> . Acesso em: jan. 2012.

IBGE - Instituto Brasileiro de Geografia e Estatística. Censo Demográfico 2010. Disponível em: <http://www.ibge.gov.br/home/estatistica/populacao/censo2010/ calendario.shtm/>. Acesso em: jan. 2012.

ICOPH - International Council of Ophthalmology. Visual Standards Aspects and Ranges of Vision Loss: wiht Emphasis on Population Surveys (2002). Disponivel em: 
<http://www.icoph.org/>. Acesso em: fev. 2013.

JIMÉNEZ, J.; OLEA, J.; TORRES, J.; ALONSO, I.; HARDER, D.; FISCHER, K. Biography of Louis Braille and Invention of the Braille Alphabet. Survey of Ophthalmology, Plymouth, v. 54, n. 1, pp. 142-149, 2009.

JOHNSON, F. Film School for Slideware: Film, Comics, and Slideshows as Sequential Art. Computers and Composition, Missouri, v. 29, n. 2, pp. 124-136, 2012. MACEDO, C. M. S.; ULBRICHT, V. R. Accessibility Guidelines for the Development of Learning Objects. Procedia Computer Science, New Orleans, v. 14, pp. 155-162, 2012.

MANTOAN, M. T. E. O desafio das diferenças nas escolas. $3^{a}$. ed. v. 1. 152p. Petrópolis/ RJ: Vozes, 2011.

MANTOAN, M. T. E.; ROPOLI, E. A.; GIFFONI, F. A. O. Caminhos de uma formação: educação especial na perspectiva de inclusão. 1. ed. v. 1. 138p. São Paulo: Petrópolis, 2012.

MANZINI, E. J.; MARQUEZINE, M. C.; TANAKA, E. D. O.; FUJISAWA, D. S.; BUSTO, R. M. Linguagem e comunicação alternativa. 1. ed. v. 1. 140p. Londrina: ABPEE, 2009.

MARCONE, R.; PENTEADO, M. G. Teaching mathematics for blind students: a challenge at the University. International Journal for Research in Mathematics Education, São Paulo, v. 3, pp. 23-35, 2013.

MARQUES, L. C.; ALMEIDA, M. A. Aplicação de recursos de acessibilidade em informática para alunos com baixa visão. Revista Educação Especial, Santa Maria, v. 26, n. 46, pp. 421-436, 2013.

MASHAL, N.; KASIRER, A. The relationship between visual metaphor comprehension and recognition of similarities in children with learning disabilities. Research in Developmental Disabilities, Baton Rouge, v. 33, n. 6, pp. 1741-1748, 2012.

MATSUDA, Y.; SAKUMA, I.; JIMBO, Y.; KOBAYASHI, E.; ARAFUNE, T.; ISOMURA, T. Emotional Communication in Finger Braille. Advances in Human-Computer Interaction, Gainesville, v. 2010, pp. 368 - 371, 2010.

MAZZOTTA, M. J. S. Educação Escolar: Comum ou Especial? 1. ed. v. 1. 124 p. São Paulo: Pioneira, 1987.

MAZZOTTA, M. J. S. Educação Especial no Brasil. História e políticas públicas. $6 a$. ed. v. 1. 231 p. São Paulo: Cortez Editora, 2011.

MEC - Ministério da Educação. Banco Internacional de Objetos Educacionais. Disponível em: <http://www.merlot.org/>. Acesso em: mar. 2013.

MERLOT - Multimedia Educational Resource for Learning and Online Teaching. Learning Objects. Disponível em: <http://www.merlot.org/>. Acesso em: mar. 2013. MINC - Ministério da Cultura. Livros para Cegos. Disponível em: <http://www. cultura.gov.br/>. Acesso em: mar. 2013. 
MORENO, J. E. R. Adaptation of Learning Strategies in Learning Objects for using Learning Styles. IERI Procedia, Shanghai,v. 2, pp. 808-814, 2012.

MORIN, E. Science avec Conscience. 315p. Fayard: Paris. 1982.

NICOLAIEWSKY, C. A.; CORREA, J. Escrita ortográfica e revisão de texto em Braille: uma história de reconstrução de paradigmas sobre o aprender. Caderno Cedes, Campinas, v. 28, n. 75, pp. 229-244, 2008.

PARK, H. W.; LEYDESDORFF, L. Decomposing social and semantic networks in emerging "big data" research. Journal of Informetrics, Diepenbeek, v. 7, pp. 756765, 2013.

PRETO, V. O. Adaptação de livros de literatura infantil para alunos com Deficiência Visual. 2009. Dissertação (Mestrado em Educação) Faculdade de Filosofia e Ciências de Marília, Universidade Estadual Paulista "Júlio de Mesquita Filho", Marília. 2009.

RABELLO, S.; MOTTI, T. F. G.; GASPARETTO, M. E. R. F. Avaliação Educacional por meio do Teste IAR em escolares com Cegueira. Revista Brasileira de Educação Especial, Marília, v.13, n.2, pp.281-290, 2007.

REFUVEILLE, P. Les nouvelles technologies à l'usage des malvoyants et des nonvoyants. Revue Francophone d'Orthoptie, Nantes, v. 5, n. 1, pp. 29-39, 2012.

SANKAKO, A. N. Sugestões para professores de orientação e mobilidade a partir de um estudo da marcha de alunos com deficiência visual. 2009. Dissertação (Mestrado em Educação), Faculdade de Filosofia e Ciências de Marília, Universidade Estadual Paulista "Júlio de Mesquita Filho", Marília. 2009.

SCHLÜNZEN, E. T. M.; RINALDI, R. P. Formação de Educadores: Compromisso com a Educação Especial na Perspectiva da Educação Inclusiva. 01. ed. v. 01. 190p. São Carlos/SP: ABPEE: Marquezine \& Manzini, 2014.

SCHMIDT, S.; TINTI, C.; FANTINO, M.; MAMMARELLA, I. C.; CORNOLDI, C. Spatial representations in blind people: The role of strategies and mobility skills. Acta Psychologica, Rotterdam, v. 142, n. 1, pp. 43-50, 2013.

SILVA, P. F.; KRASILCHIK, M. Bioética e ensino de ciências: o tratamento de temas controversos - dificuldades apresentadas por futuros professores de ciências e de biologia. Ciências e Educação, Bauru, v. 19, n. 2, pp. 379-392, 2013.

TORRES, E. F.; MAZZONI, A. A.; MELLO, A. G. Nem toda pessoa cega lê em Braille nem toda pessoa surda se comunica em língua de sinais. Educação e Pesquisa, São Paulo, v. 33, n. 2, pp. 369-385, 2007.

TIXIER, M.; LENAY, C.; GAPENNE, 0.; AUBERT, D. From perceptual supplementation to the accessibility of digital spaces: The case of free exploration of city maps for blind person. IRBM, Rennes, v. 34, n. 1, pp. 64-68, 2013.

VEISPAK, A.; BOETS, B.; GHESQUIÈRE, P. Differential cognitive and perceptual correlates of print reading versus braille Reading. Research in Developmental 
Disabilities, Baton Rouge, v. 34, n. 1, pp. 372-385, 2013.

WHO - World Health Organization. Prevention of Blindness and Visual Impairment. Disponível em: <http://www.who.int/blindness/ >. Acesso em: fev. 2013.

YENI, S. An Analysis on Teachers' and Teacher Candidates' Usage of Internet Based Materials and Awareness of Learning Objects. Procedia - Social and Behavioral Sciences, Barcelona, v. 46, pp. 1914-1918, 2012.

Recebido em maio de 2014

Aprovado em agosto de 2014

Otacílio Antunes Santana é doutor em ciências florestais pela Universidade de Brasília (UnB), com estágio de doutorado na Georg-August Universität Göttingen/ Alemanha. É Professor Adjunto da Universidade Federal de Pernambuco (UFPE), no Centro de Ciências Biológicas (CCB), Departamento de Biofísica e Radiobiologia. E-mail: otaciliosantanađgmail.com 